\title{
Analysis of Genetic Diversity in Sorghum [Sorghum bicolor (L.)] Accessions of Maharashtra as Estimated by Simple Sequence Repeats (SSR)
}

\author{
C. Kshirsagar Ram, S. Kale Sonam*, R. Chavan Narendra and V. Kore Ganesh \\ Dept. of Plant Biotechnology, MGM College of Agricultural Biotechnology (CABT), \\ Vasantrao Naik Marathwada Krishi Vidyapeeth, Gandheli, Aurangabad-431003, \\ Maharashtra, India \\ *Corresponding author
}

Keywords

Cereal crops,

Breeding,

Biological status,

Gene diversity

\section{Article Info}

Accepted:

10 March 2020

Available Online:

10 April 2020

\section{A B S T R A C T}

Sorghum bicolor is most important cereal crops around the world where the availability of water is less. Study of genetic variability among the sorghum accessions will enable accurate results in breeding programme and in mapping studies. By using SSR markers evenly distributed on sorghum genome revealed that, all the 20 accessions originated from Marathwada (Maharashtra) region were grouped into three main classes and it show correlation with the biological status and other characteristics features of accessions. The gene diversity measured in term of polymorphic information content (PIC) was ranged between 0.41 to 0.63 with the average PIC value was found to be 0.53 where 0.41 PIC value indicated presence of three allele per locus. The SSR loci Xtxp278, msbCIR276, Xisep0310, Xtxp321, Xtxp141 and Xtxp145 were rich in allelic diversity exhibiting highest PIC value. Expected heterozygosity or Gene diversity computed according to Nei (1973) and varied from 0.46 to 0.68 with an average of 0.60 .

\section{Introduction}

Sorghum [Sorghum bicolor (L.), $2 \mathrm{n}=2 \mathrm{x}=$ 20] is the fifth most important cereal crop in the world after wheat, Rice, Maize and Barley, with over $80 \%$ of the crop in Africa and Asia (FAOSTAT, 2017). Sorghum is popularly known as "jowar" in Bangladesh and India. It is used as a staple food and fodder crop and has gained the status of a 'failsafe' crop in global agro- ecosystems. Sorghum is also used for the production of Ethanol, Starch and Syrup in the brewing industry. It is widely adapted to harsh environmental conditions, and more specifically to arid and semi-arid regions of 
the world. Sorghum is known as 'the camel amongst crops' and requires much less water than many other cereals and has a remarkable ability to produce a crop under low levels of inputs and adverse stress conditions (Zheng et al., 2011). It is currently a model crop for tropical grasses that employ $\mathrm{C} 4$ photosynthesis because of the availability of its complete genome sequence (Billot et al., 2013)

S. bicolor has three subspecies, namely arundinaceum, bicolor and drummondii, and the cultivated sorghums are all from bicolor, which has five local races, bicolor, caudatum, durra, guinea and kafir (Harlan, 1972). Sorghum bicolor contains both cultivated and wild relative races, and it provides a substantial amount of genetic diversity for traits of agronomic importance so as to develop the crop's different variety of interest for plant breeders. Sorghum has one of the largest crop germplasm collections, consisting of more than 42,000 accessions worldwide. The largest diversity of the crop germplasm provides greater opportunities for improvement regarding its environmental adaptability and acquiring better agronomic traits from the crop species.

Assessment of genetic diversity within cultivated crops is crucial for the effective utilization of crop genetic resources. It is particularly useful in characterization of accessions (Smith et al., 2000), in identifying duplicates in germplasm collections (Dean et al., 1999) and in the choice of parents in breeding programmes (Gupta et al., 1994, 1996). The more variable genotypes or accessions can be crossed to produce better varieties that can tolerate a range of environmental changes to abiotic and biotic stresses. Therefore, a better understanding of the genetic diversity in sorghum crop species will definitely facilitate the further improvement of this cereal crop concerning its genetic architecture (Tesfaye, 2017).
Genetic variation consists of sequence variation and structure alteration. Sequence variation normally is manifested by SNPs, short sequence insertions and deletions (indels), microsatellites or simple sequence repeats, and transposable elements. Many molecular marker technologies have been developed and applied for studying patterns of genetic diversity in sorghum (Ghebru et al., 2002; Folkertsma et al., 2005; Ali et al., 2008; Bhosale et al., 2011). Simple sequence repeat (SSR) are the markers of choice in the study as they are polymerase chain reaction (PCR)-based, easy to use, locus-specific, codominant, highly reproducible, hypervariable and informative (Powell et al., 1996).

Biochemical genetic markers provided the first assessment of neutral genetic variation and enabled demarcation of groups by race and origin. Several strategies have been used for the analysis of diversity which uses morphological, geographical, biochemical and molecular differences among the accessions (Franco et al., 2001; Mohammadi et al., 2003; Smith et al., 2000; Ghebru et al., 2002; Chiorato et al., 2007). Several generations of DNA-based molecular markers were then used and refined the assessment.

In the early 1990s, restriction fragment length polymorphism (RFLP) markers were effectively utilized for sorghum diversity analysis, genetic mapping and comparative genome mapping. Later other marker systems were tried, including randomly amplified poly- morphic DNAs (RAPDs) (Ayana and Bekele, 2000; Prakash et al., 2006), simple sequence repeats (SSRs) (Dje et al., 2000), and amplified fragment length polymorphisms (AFLPs). These markers systems, independently or in combination with others, were efficiently used for sorghum genetic diversity analysis. SSRs were developed independently by several different research groups and were exploited for genetic diversity analysis. 
In the present study the 20 sorghum accessions originated from Marathwada (Maharashtra) region of Maharashtra consisting of advance/improved cultivar, traditional cultivar/landrace, breeding/ research material were analysed for genetic diversity in order to exploit the use of genetic resources for crop breeding and various mapping studies.

The aim of the present study is to characterize genetic structure of sorghum accessions as an initiative step in testing, the applicability of molecular markers for choosing parents, eight sorghum SSR markers evenly distributed on sorghum genome were used to analyses the genetic variation among different germplasm accessions. The objectives of this study are

To analysed the characteristics of the SSR loci and genotypic structure of sorghum accessions

To know the genetic variation within sorghum accessions.

\section{Materials and Methods}

\section{Plant material}

The 20 Sorghum accessions used in the present investigation were procured from 'International Crop Research Institute for Semi-Arid and Tropics' (ICRISAT) gene bank and were evaluated for genetic diversity study. The sorghum accessions were originated from Marathwada region in Maharashtra state where sorghum is an important cereal crop because of its adaptation to environmental conditions. The biological status and the line grouping of the sorghum accessions are listed in the table 1.

\section{DNA extraction}

Sorghum seeds of 20 accessions were sown in pots under polyhouse at MGM College of Agricultural Biotechnology, Gandheli,
Aurangabad during Rabi-December 2019. The seedlings were allowed to grow for 20-22 days. The leaf samples were collected from all 20 accessions and store at $-20^{\circ} \mathrm{C}$ until use. Genomic DNA was extracted from $0.2 \mathrm{~g}$ fresh leaf sample using modified CTAB protocol modified at Department of Plant Biotechnology (Kale et al., 2020) (CABT, Aurangabad). The yield of genomic DNA obtained was $1700-3700 \mathrm{ng} / \mu \mathrm{l}$. DNA of all the extracts diluted to $50 \mathrm{ng} / \mu \mathrm{l}$ was used for the PCR amplification.

\section{SSR markers}

Eight pairs of SSR primers (SSR Markers) were used in the study (Table 2). Primer pairs were chosen on the basis of their properties of detecting single loci, their broad coverage of the genome and their high levels of polymorphism when applied to a broad range of Sorghum germplasm. The sequence of the eight primer pairs were chosen from the sorghum SSR kit (http://sorghum.cirad. fr/SSR_kit) (Billot et al., 2013).

\section{PCR amplification}

Eight SSR primer pairs were used to detect polymorphism among the 20 sorghum accessions. The PCR was performed in a volume of $20 \mu \mathrm{l}$ reaction containing $2 \mu \mathrm{l}$ (50ng) genomic DNA, 10X PCR buffer with $25 \mathrm{mM} \mathrm{MgCl} 2(2.0 \mu \mathrm{l}), 2 \mathrm{mM}$ dNTPs $(2.0 \mu \mathrm{l})$, $10 \mu \mathrm{M}$ forward and reverse primer $(2.0 \mu \mathrm{l}), 1 \mu \mathrm{l}$

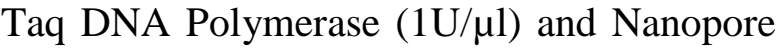
water. For the maximum yield and specificity, annealing temperature and cycling duration was rearranged for each primer pair. Amplification was performed in an APPLIED BIOSYSTEM thermal cycler with an initial denaturation at $94^{\circ} \mathrm{C}$ for 5 mins followed by 34 cycles at $94^{\circ} \mathrm{C}$ for $30 \mathrm{sec}, 55-65^{\circ} \mathrm{C}$ for 30 sec (depending on primer Tm) and $72^{\circ} \mathrm{C}$ for $1 \mathrm{~min}$, followed by a final extensions at $72^{\circ} \mathrm{C}$ for $7 \mathrm{mins}$. 


\section{Gel electrophoresis and detection}

The amplified PCR products for each marker were resolved on agarose gel for detection of amplified product. For the visualization of the DNA fragments and to identify small polymorphic differences between them, 5-6 $\mu$ l of Bromophenol blue dye was added to $20 \mu \mathrm{l}$ of the PCR product.

Agarose gel of $3.5 \%$ was used for better resolution of PCR product. $20 \mu \mathrm{l}$ of the sample was loaded into the wells in gel with $1 \mathrm{X}$ TAE buffer with 100 bp DNA ladder (Genei) and the electrophoresis unit was operated at 200 volts. The gel was visualized under UV transilluminator and $\mathrm{Gel}$ documentation unit and the fragment sizes for each marker were determined. The size of the fragments was determined using the $100 \mathrm{bp}$ DNA ladder and the scoring of markers was performed for each fragment.

\section{Statistical analysis}

For the estimation of genetic diversity for each primer, parameters such as number of alleles per locus, heterozygosity, major allele frequency, gene diversity and polymorphic information content (PIC) for each marker were estimated using Powermarker version 3.25 (Liu et al., 2005) Allele frequency represents the frequency of particular allele for each marker.

Heterozygosity is a proportion of heterozygous individual in the population. Polymorphic information content (PIC) represents the amount of polymorphism within a population. Nei's distance (Nei et al., 1973) was calculated and used for the construction of phylogenetic tree and unrooted phylogeny using neighbour-joining (NJ) method, bootstrapping of the data (10,000 permutations) as implemented in POWERMARKER, and MEGA 6.0 was used to visualize the Tree (Tamura et al., 2007).

\section{Results and Discussion}

Characteristics of the SSR loci and genotypic structure of sorghum accessions

Analysis of genetic structure of the germplasm population is an important for the plant breeding programme and for association studies to identify the superior alleles in the accessions (Nachimuthu et al., 2015). In this study attempt has been made to analyse the genetic structure of twenty sorghum accessions using evenly distributed eight SSR markers on sorghum genome that show amplification and polymorphism with different allele size (140-250bp). All the markers produce all expected SSR allele size amplicons were used for analysis of genetic diversity among the twenty accessions of elite sorghum. Thus, all these markers should represent the genetic diversity among sorghum accessions.

In total 27 alleles were detected in 20 germplasm accessions. The number of alleles per loci ranged from 3 (msbCIR276, xtxp021, xisep0310, gpsb089 and xtxp145) to $4(x \operatorname{txp} 278, x \operatorname{txp} 321$ and $x \operatorname{txp} 141)$ with an average of 3.37 alleles per locus (Table 3). The fragment size of the alleles ranged from 140 bp (Xtxp141) to 250 bp (Xtxp278; Table 4). All the SSR loci show polymorphism. Similar results were reported in the previous studies were, the average of 4.4 (Nguni et al., 2011), 3.44 (Billot et al., 2013) alleles were observed.

\section{Genetic variation within sorghum} accessions and cluster analysis

Analysis of genetic diversity among 20 accessions revealed that the polymorphic Information Content (PIC) value represents the relative informativeness of each marker loci and in this study, the average PIC value was found to be 0.53 was comparable to past and earlier reports for sorghum and rice (Cho 
et al., 2000; Jain et al., 2004; Nachimuthu et al., 2015). PIC values was found to be ranged from 0.41 to 0.63 where 0.41 PIC value indicated presence of three allele per locus.

Out of eight polymorphic SSR loci, six (75.0\%) markers were highly informative (PIC $\geq 0.5)$, two markers $(25 \%)$ were reasonably informative (PIC $=0.25-0.5$ ) and no one markers was found to be less informative (PIC $\leq 0.25$ ). No heterozygosity was found across 20 accessions which may be due to autogamous nature of sorghum. The SSR loci Xtxp278, msbCIR276, Xisep0310, Xtxp321, Xtxp141 and Xtxp145 were rich in allelic diversity exhibiting highest PIC value (Table 4).

Expected heterozygosity or Gene diversity computed according to Nei (1973) and varied from 0.46 to 0.68 with an average of 0.60 . The major allele frequency across 20 accessions was ranged from 0.35 to 0.75 with the mean major allele frequency was 0.51 (Table 3). Thus, the present result revealed that 20 sorghum accessions used in this study have wide genetic diversity and are good candidates for candidate gene specific association studies of complex trait such as yield and for using parents in plant breeding programme.

The main focused of this study was the analysis of variation between the different races of sorghum using SSR markers. Some important findings were published by the authors on diversity analysis in sorghum accession from different origins.

The genetic diversity within small sets of Guinea-race sorghum accessions has been analyzed in the past studies using different molecular markers such as, SSR markers (Dje et al., 2000), random amplified polymorphic DNA (RAPD) markers (de Oliveira et al., 1996; Ayana and Bekele, 2000; Prakash et al.,
2006; Dahlberg et al., 2002) and restriction fragment length polymorphism (RFLP) markers (Deu et al., 1994).

Employing SSR markers to analyse the genetic diversity is more accurate and adventitious because of their abundance on the genome, co-dominance, reproducibility and ease of use.

The availability of complete sorghum genomic sequence information (Paterson et al., 2009) on various databases, a number of genome-wide SSRs have been published and available with their sequences in sorghum and have been employed in genetic diversity and other studies.

Estimation of major allele frequency, allele number, gene diversity and PIC value with the use of evenly distributed SSR is more reliable and accurate than the use of other system. It was observed that, the PIC value obtained in this study (Mean PIC $=0.53$ ) is similar to the diversity value $(0.40,0.46,0.62$, 0.58) reported by(Ali et al., 2008; Schloss et al., 2002; Agrama et al., 2008; Smith et al., 2000) respectively.

PIC provides an estimate of the discriminatory power of a locus or loci by the number of alleles expressed and the relative frequencies of those alleles. The genetic variation among five Guinea-race sorghum accessions (Dje etal.,2000), revealed an observed average expected gene diversity of 0.22 which was much lesser than the gene diversity obtained in the current study (0.6) using 20 sorghum accessions originated from Marathwada region of Maharashtra, India. As observed by Chakauya et al., (2006), differences in the genetic diversity could be attributed to traditional farming systems with agronomic, economic and cultural considerations that foster high levels of genetic diversity. 
Also the diversity of sorghum types, varieties, and traditional cultivars/races has been related to movement of people, disruptive selection, geographic isolation, gene flow from wild to cultivated plants, and recombination of these types in different environments (Doggett, 1988; Wet and Huckabay, 1967; Harlan, 1976). Distance based approach which is based on calculating pair wise distance matrix was computed by calculating a dissimilarity matrix using a Nei distance (1973) and used for the construction of phylogenetic tree by Neighbour-Joining (NJ) method, implemented in POWERMARKER version 3.25 and the tree was viewed using MEGA $\mathrm{V}$ 6.0. A neighbour-joining $(\mathrm{NJ})$ tree was constructed based on genetic distance (Figure 1).

The group I and group II in NJ tree consists of the traditional landraces and breeding lines but group I was dominated by traditional landraces whereas the II group consists of mostly breeding material. Group III of NJ tree is dominated by advance/improve cultivars. Similar observations were arrived by many investigators in different crops Nachimuthu et al., 2015; Agrama et al., 2007; Choudhury et al., 2014; Muthukumar et al., 2015;Nguni et al., 2011).

Table.1 Details of sorghum accessions used in the study

\begin{tabular}{|l|l|l|l|l|}
\hline Sr.no. & Accession ID & $\begin{array}{l}\text { Code } \\
\text { no. }\end{array}$ & Biological status & Collection Site \\
\hline $\mathbf{1}$ & Dukri & G1 & Traditional cultivar/Landrace & Aurangabad;Aurangabad district \\
\hline $\mathbf{2}$ & $\begin{array}{l}\text { Chetapuri } \\
\text { bhendala }\end{array}$ & G2 & Traditional cultivar/Landrace & Aurangabad;Aurangabad district \\
\hline $\mathbf{3}$ & PJ1K & G3 & Advanced/Improved cultivar & Parbhani; Parbhani district \\
\hline $\mathbf{4}$ & PJ3R & G4 & Breeding/Research material & Parbhani; Parbhani district \\
\hline $\mathbf{5}$ & SM Wani No.7 & G5 & Traditional cultivar/Landrace & Parbhani; Parbhani district \\
\hline $\mathbf{6}$ & PJ14R & G6 & Advanced/Improved cultivar & Parbhani; Parbhani district \\
\hline $\mathbf{7}$ & NSL 50400 & G7 & Traditional cultivar/Landrace & Parbhani; Parbhani district \\
\hline $\mathbf{8}$ & PJ36K & G8 & Advanced/Improved cultivar & Parbhani; Parbhani district \\
\hline $\mathbf{9}$ & PJ5R & G9 & Advanced/Improved cultivar & Parbhani; Parbhani district \\
\hline $\mathbf{1 0}$ & IC 9185 & G10 & Traditional cultivar/Landrace & Parbhani; Parbhani district \\
\hline $\mathbf{1 1}$ & IC 9186 & G11 & Traditional cultivar/Landrace & Parbhani; Parbhani district \\
\hline $\mathbf{1 2}$ & IC 8844 & G12 & Traditional cultivar/Landrace & Parbhani; Parbhani district \\
\hline $\mathbf{1 3}$ & IC 8857 & G13 & Traditional cultivar/Landrace & Parbhani; Parbhani district \\
\hline $\mathbf{1 4}$ & IC 8868 & G14 & Traditional cultivar/Landrace & Parbhani; Parbhani district \\
\hline $\mathbf{1 5}$ & IC 8889 & G15 & Traditional cultivar/Landrace & Parbhani; Parbhani district \\
\hline $\mathbf{1 6}$ & PJ13R & G16 & Breeding/Research material & Parbhani; Parbhani district \\
\hline $\mathbf{1 7}$ & PJ14R & G17 & Breeding/Research material & Parbhani; Parbhani district \\
\hline $\mathbf{1 8}$ & PJ15R & G18 & Breeding/Research material & Parbhani; Parbhani district \\
\hline $\mathbf{1 9}$ & PJ16R & G19 & Breeding/Research material & Parbhani; Parbhani district \\
\hline $\mathbf{2 0}$ & PJ17R & G20 & Breeding/Research material & Parbhani; Parbhani district \\
\hline & & & & \\
\hline
\end{tabular}


Table.2 Characteristic of the eight SSR loci analyzed for diversity study

\begin{tabular}{|l|l|l|l|l|l|}
\hline Sr.no & $\begin{array}{l}\text { Marker } \\
\text { Name }\end{array}$ & Forward Primer & Reverse Primer & Allele Size & Ch. No \\
\hline $\mathbf{1}$ & Xtxp321 & TAACCCAAGCCTGAGCATAAGA & CCCATTCACACATGAGACGAG & $192-252$ & SBI08 \\
\hline $\mathbf{2}$ & MsbCIR276 & CCCCAATCTAACTATTTGGT & GAGGCTGAGATGCTCTGT & $230-234$ & SBI03 \\
\hline $\mathbf{3}$ & Xtxp021 & GAGCTGCCATAGATTTGGTCG & ACCTCGTCCCACCTTTGTTG & $169-199$ & SBI04 \\
\hline $\mathbf{4}$ & Xtxp141 & TGTATGGCCTAGCTTATCT & CAACAAGCCAACCTAAA & $135-167$ & SBI10 \\
\hline $\mathbf{5}$ & Xtxp278 & $\begin{array}{l}\text { GGGTTTCAACTCTAGCCTACCGAA } \\
\text { CTTCCT }\end{array}$ & $\begin{array}{l}\text { ATGCCTCATCATGGTTCGTTTT } \\
\text { GCTT }\end{array}$ & $243-252$ & SBI07 \\
\hline $\mathbf{6}$ & Xisep0310 & TGCCTTGTGCCTTGTTTATCT & GGATCGATGCCTATCTCGTC & $164-219$ & SBI02 \\
\hline $\mathbf{7}$ & gpsb089 & ATCAGGTACAGCAGGTAGG & ATGCATCATGGCTGGT & $165-173$ & SBI01 \\
\hline $\mathbf{8}$ & Xtxp145 & GTTCCTCCTGCCATTACT & CTTCCGCACATCCAC & $208-244$ & SBI06 \\
\hline
\end{tabular}

Table.3 Mean diversity analysis of 20 germplasm accessions using eight SSR markers

\begin{tabular}{|c|c|c|c|c|}
\hline S. No. & Diversity Traits & Number & Range & \\
\hline $\mathbf{1}$ & Total no. of alleles & 27 & Maximum & Minimum \\
\hline $\mathbf{2}$ & $\begin{array}{c}\text { Mean no. of alleles per } \\
\text { locus }\end{array}$ & 3.3 & 4 & 3 \\
\hline $\mathbf{3}$ & $\begin{array}{c}\text { Mean major allele } \\
\text { frequency }\end{array}$ & 0.51 & 0.75 & 0.35 \\
\hline $\mathbf{4}$ & Mean Gene Diversity & 0.6 & 0.76 & 0.41 \\
\hline $\mathbf{5}$ & Mean PIC & 0.53 & 0.72 & 0.38 \\
\hline
\end{tabular}

Table.4 Details of SSR loci used for genotyping in the sorghum accessions and their genetic diversity parameters using power marker V 3.25 program

\begin{tabular}{|c|c|c|c|c|c|c|c|}
\hline Marker & $\begin{array}{c}\text { Chr. } \\
\text { no. }\end{array}$ & $\begin{array}{c}\text { Minimum } \\
\text { molecular } \\
\text { weight }\end{array}$ & $\begin{array}{c}\text { Maximum } \\
\text { molecular } \\
\text { weight }\end{array}$ & $\begin{array}{c}\text { Major } \\
\text { Allele } \\
\text { Frequency }\end{array}$ & Allele No & $\begin{array}{c}\text { Gene } \\
\text { Diversity }\end{array}$ & PIC \\
\hline xtxp278 & 7 & 235 & 250 & 0.45 & 4.0 & 0.6850 & 0.6324 \\
\hline msbCIR276 & 3 & 230 & 240 & 0.50 & 3.0 & 0.6050 & 0.5270 \\
\hline xtxp021 & 4 & 180 & 200 & 0.65 & 3.0 & 0.5150 & 0.4604 \\
\hline xisep0310 & 2 & 200 & 220 & 0.50 & 3.0 & 0.6250 & 0.5547 \\
\hline xtxp321 & 8 & 195 & 220 & 0.50 & 4.0 & 0.5850 & 0.5009 \\
\hline gpsb089 & 1 & 180 & 190 & 0.70 & 3.0 & 0.4650 & 0.4199 \\
\hline xtxp141 & 10 & 140 & 170 & 0.40 & 4.0 & 0.6850 & 0.6270 \\
\hline xtxp145 & 6 & 220 & 240 & 0.45 & 3.0 & 0.6450 & 0.5720 \\
\hline
\end{tabular}




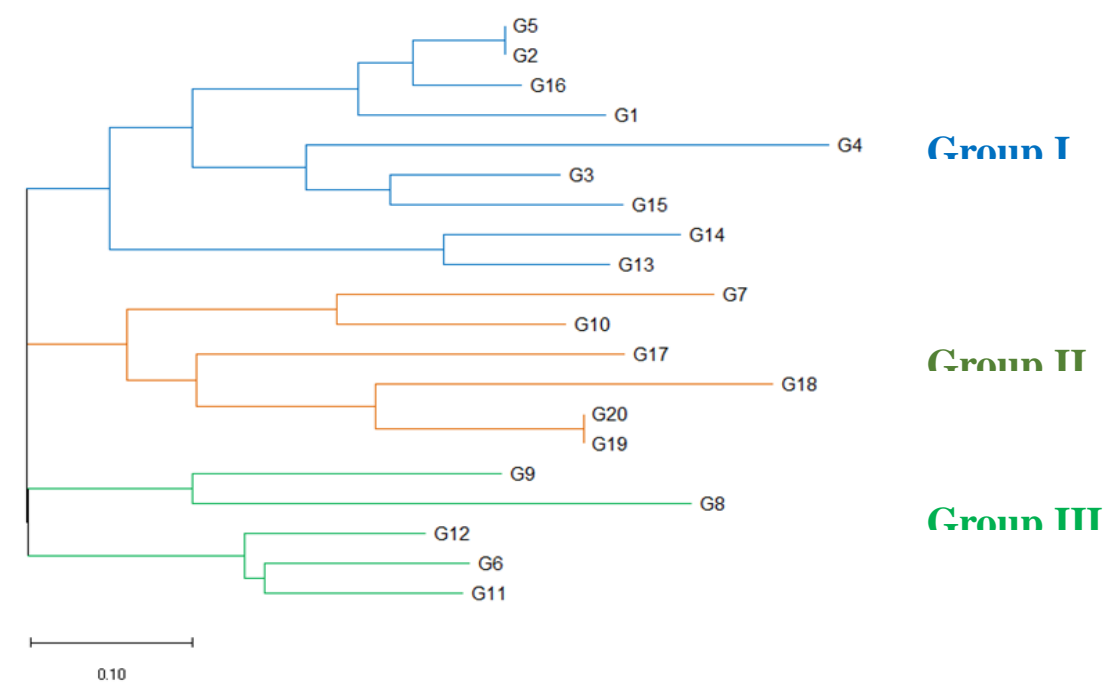

Fig.1 Neighbor-joining (NJ) tree of 20 Sorghum accessions constructed using POWERMARKER software

Cluster analyses in the collection of sorghum accessions provided important evidence to define breeding strategies and to identify superior parents for the development of new hybrid sorghum cultivars with the major focus on various biotic abiotic stresses.

Also the assessment of diversity and analysis of population structure is requiring for analysis and identification of quantitative trait loci by means of association mapping (Muthukumar et al., 2015). In the present study all lines were distinctly placed in this dendogram obtained by the molecular diversity analysis were more consistent with the some important characteristics traits and the historic background of the sorghum accessions.

Total 20 accessions were grouped into three main clusters and sub-sub groups based on the molecular marker data generated from evenly distributed SSR markers on the whole genome of sorghum. No much significant results were reported in the previous study based on the phenotypic data used to classify sorghum accessions. Limitations on use of morphological traits, their experimental costs, effect of environment, evaluation time and genotype $\times$ environment interactions are widely discussed (Fufa et al., 2005; Chandra et al., 2002). In this context, DNA-based SSR markers have become powerful application tools for illustrating and quantifying genetic differences within and among the various crop species.

The SSR marker analysis revealed genetic variation among the sorghum genotypes. Compare with other marker system present study used the SSR markers that proven the utility of sorghum SSR markers in understanding the genetic similarities and discrimination among a set of sorghum genotypes. Based on previous studies analysis, it is more accurate to find out the genetic structure of any germplasm collection at molecular level than that using agromorphological characteristic of accessions. Abundant genetic diversity exists in the germplasm accessions at genetic level and it is easy to find out. The results of statistical analysis reflects the broad genetic variability was existed across the germplasm accessions 
that provided the scope to identify the allelic variants (superior alleles) through candidate gene based association mapping approach in sorghum breeding program.

\section{Acknowledgement}

The authors gratefully acknowledge ICRISAT, Hyderabad, MGM College of Agricultural Biotechnology and MGM Institute of Bioscience and Technology, Aurangabad.

\section{References}

Agrama, H., Eizenga, G., and Yan, W. 2007. Association mapping of yield and its components in rice cultivars. Molecular Breeding. 19(4): 341-356.

Agrama, H., and Eizenga, G. 2008. Molecular diversity and genome-wide linkage disequilibrium patterns in a worldwide collection of Oryza sativa and its wild relatives. Euphytica. 160(3): 339-355.

Ali, Y., Atta, BM., Akhter, J., Monneveux, P., and Lateef, Z. 2008. Genetic variability, association and diversity studies in wheat (Triticum aestivum L.) germplasm. Pak. J. Bot. 40(5): 2087-2097.

Ayana, A. and Bekele, E. 2000. Geographical patterns of morphological variation in sorghum (Sorghum bicolor (L.) Moench) germplasm from Ethiopia and Eritrea: Quantitative characters. Euphytica, 115(2): 91-104.

Bhosale, US., Stich, B., Rattunde, WFH., Weitzein, E., Haussmann, GIB., Hash, TC., Melchinger, EA,. and Parzies, KH. 2011. Population structure in sorghum accessions from west Africa differing in races and maturity class. Genetica. 139(4): 453-463.

Billot, C., Ramu, P., Bouchet, S., Chantereau, J., and Deu, M., et al., 2013. Massive Sorghum Collection Genotyped with SSR Markers to Enhance Use of Global Genetic Resources. PLoS ONE. 8(4): e59714.

Chakauya, E., Tongoona, P., Matiburi, EA., and Grum, M. 2006. Genetic diversity assessment of sorghum landraces in Zimbabwe using microsatellites and indigenous local names. International Journal of Botany. 2(1):219-222.

Chandra, S., Huaman, Z., Hari Krishna, S., and Ortiz, R. 2002. Optimal sampling strategy and core collection size of Andean tetraploid potato based on isozyme data-a simulation study. Theor. Appl. Genet. 104(8): 1325- 1334.

Chiorato, AF., Carbonell, SAM., Benchimol, LL., Chiavegato, MB., Dias, LAS., and Colombo, CA. 2007. Genetic diversity in common bean accessions evaluated by means of morpho-agronomical and RAPD data. Sci Agr. 64(3):256-262.

Cho, YG., Ishii, T., Temnykh, S., Chen, X., Lipovich, L., and McCOUCH, SR. et al., 2000. Diversity of microsatellites derived from genomic libraries and GenBank sequences in rice (Oryza sativa L.). Theor Appl Genet. 100(5): 713-722.

Choudhury, DR., Singh, N., Singh, AK., Kumar, S., Srinivasan, K., and Tyagi, R. et al., 2014. Analysis of genetic diversity and population structure of rice germplasm from North-eastern region of India and development of a core germplasm set. PLoS ONE. 9(11): e113094.

Dahlberg, JA., Zhang, X., Hart, GE., and Mullet, JE. 2002. Comparative assessment of variation among sorghum germplasm accessions using seed morphology and RAPD Measurements. Crop Sci. 42(1):291-296.

de Oliveira, AC., Richter, T., and Bennetzen, JL. 1996. Regional and racial specificities in sorghum germplasm assessed with DNA markers. Genome. 39 (3):579-587.

Dean, RE., Dahlberg, JA., Hopkins, MS., Mitchell, SE., and Kresovich, S. 1999. Genetic redundancy and diversity among 'orange' accessions in the US National Sorghum Collection as assessed with simple sequence repeat (SSR) markers. Crop Science. 39(4):1215-1221.

Deu, M., Gonzalez-de-Leon, D., Glaszmann, JC., Degremont, I., Chantereau, J., Lanaud, C., and Hamon, P. 1994. RFLP diversity in 
cultivated sorghum in relation to racial differentiation. Theor Appl Genet. 88(6/7):838-844.

De-Wet, J., and Huckabay, J. 1967. The origin of Sorghum bicolor. II. Distribution and domestication. Evolution. 21(4):787-802.

Dje, Y., Heuretz, M., Lefebvre, C., and Vekemans, X. 2000. Assessment of genetic diversity within and among germplasm accessions in cultivated sorghum using micro satellite markers. Theor. Applied Genet. 100 (1): 918-925.

Doggett, H. 1988. Sorghum. 2(Ed.) Harlow, Essex, England: Longman Scientific \& Technical; New York: Wiley.

FAO Satistics, 2017. Food and Agriculture Organization, www.fao.org/faostat/en.

Folkertsma, RT., Frederick, H., Rattunde, W., Chandra, S., Raju, GS., and Hash, CT. 2005. The pattern of genetic diversity of Guinea-race Sorghum bicolor (L.) Moench landraces as revealed with SSR markers. Theor Appl Genet. 111(3): 399-409.

Franco, J., Crossa, J., Ribaut, JM., Bertran, J., Warburton, ML., and Khairallah, MA. 2001. Method for combining molecular markers and phenotypic attributes for classifying plant genotypes. Theor Appl Genet. 103 (6):944-952.

Fufa, H., Baenziger, PS., Beecher, BS., Dweikat, I., and Graybosch, EKM. 2005. Comparison of phenotypic and molecular marker-based classifications of hard red winter wheat cultivars. Euphytica. 145(12): 133-146.

Ghebru, B., Schmidt, RJ., and Bennetzen, JL. 2002. Genetic diversity of Eritrean sorghum landraces assessed with simple sequence repeat (SSR) markers. Theor Appl Genet. 105(2/3): 229-236.

Gupta, M., Chyi, YS., Romero-Severson, J., and Owen, JL. 1994. Amplification of DNA markers from evolutionarily diverse genomes using single primers of simple sequence repeats. Theoretical and Applied Genetics. 89(7/8):998-1006.

Gupta, PK., Balyan, HS., Sharma, PC., and Ramesh, B. 1996. Microsatellites in plants: a new class of molecular markers. Current
Science. 70(1):45-54.

Harlan, J., Stemler, A. 1976. The races of sorghum in Africa. In: Harlan J, de Wet JM, Stemler AB, editors. Origins of African Plant Domestication. The Hague: Mouton Publishers.

Harlan, JR., and de-Wet, JMJ. 1972. A simplified classification of cultivated sorghum. Crop Science. 12(2): 172-176.

Jain, S., Jain, RK., and McCOUCH, SR. 2004. Genetic analysis of Indian aromatic and quality rice (Oryza sativa L.) germplasm using panels of fluorescently labeled microsatellite markers. Theor Appl Genet. 109(5): 965-977.

Kale, SS., Kadu, TP., Chavan, NR., and Chavan, NS. 2020. Rapid and efficient method of genomic DNA extraction from sweet sorghum [Sorghum bicolor (L.)] using leaf tissue. International Journal of Chemical Studies. 8 (1). 1166-1169.

Liu, H., Wang, S., Yu, X., Yu, J., He, X., Zhang, S., Shou, H., and Wu, P. 2005. ARL1, a LOB- domain protein required for adventitious root formation in rice. The Plant Journal. 43(1): 47-56.

Mohammadi, SA., and Prasanna, BM. 2003. Analysis of Genetic Diversity in Crop Plants-Salient Statistical Tools and Considerations Sampling Strategies. Crop Sci. 43(4):1235-1248.

Muthukumar, C., Vivek, VD., Poornima, R., Kavitha, S., Gayathri, V., and Babu, RC. 2015. Fine mapping of consistent quantitative trait loci for yield under drought stress using rice (Oryza sativa) recombinant inbred lines adapted to rainfed environment. Current sci. 109(5): 910-917.

Nachimuthu, VV., Muthurajan, R., Duraialaguraja, S., Sivakami, R., Pandian, BA., Ponniah, G., and Gunasekaran, et al., 2015. Analysis of population structure and genetic diversity in rice germplasm using SSR markers: an initiative towards association mapping of agronomic traits in Oryza Sativa. Rice. 8(1):1-30.

Nachimuthu, VV., Muthurajan, R., Duraialaguraja, S., Sivakami, R., Pandian, BA., Ponniah, G., and Gunasekaran, et al., 
2015. Analysis of population structure and genetic diversity in rice germplasm using SSR markers: an initiative towards association mapping of agronomic traits in Oryza Sativa. Rice. 8(1):1-30.

Nei, M. 1973. Analysis of gene diversity in subdivided populations. Proceedings of the National Academy of Sciences. 70(12): 3321-3323.

Nguni, D., Geleta, M., and Bryngelsson, T. 2011. Genetic diversity in sorghum (Sorghum bicolor (L.) Moench) accessions of Zambia as revealed by simple sequence repeats (SSR). Hereditas. 148(2). 52-62.

Paterson, AH., Bowers, JE., Bruggmann, R., Dubchak, I., Grimwood, J., Gundlach, H. et al., 2009. The Sorghum bicolor genome and the diversification of grasses. Nat. 29,457(7229):551-556.

Powell, W., Morgante, M., Andre, C., Hanafey, M., Vogel, J., Tingey, S., and Rafalski, A. 1996. The comparison of RFLP, RAPD, AFLP and SSR (microsatellite) markers for germplasm analysis. Mol. Breed. 2(3): 225238.

Prakash, SPJ., Biji, KR., Gomez, SM., Murthy, KG., and. Babu, RC. 2006. Genetic diversity analysis of sorghum (Sorghum bicolour L. Moench) accessions using RAPD markers. Indian J. Crop Sci. 1(1/2): 109-112.

Schloss, SJ., Mitchell, SE., White, GM, Kukatla, R., Bowers, JE., Paterson, AH., and Kresovich, S. 2002. Characterization of RFLP clone sequences for gene discovery and SSR development in Sorghum bicolor (L). Moench. Theor Appl
Genet. 105 (6/7):912-920.

Smith, JSC., Kresovich, S., Hopkins, MS., Mitchell, SE., Dean, RE., Woodman, WL., Lee, M., and Porter, K. 2000. Genetic diversity among elite sorghum inbred lines assessed with simple sequence repeats. Crop Sci. 40(1): 226-232.

Smith, JSC., Kresovich, S., Hopkins, MS., Mitchell, SE., Dean, RE., Woodman, WL., and Lee, MPK. 2000. Genetic diversity among elite sorghum inbred lines assessed with simple sequence repeats. Crop Sci. 40(1): 226-232.

Smith, JSC., Kresovich, S., Hopkins, MS., Mitchell, SE., Dean, RE., Woodman, WL., Lee, M., and Porter, K. 2000. Genetic diversity among elite sorghum inbred lines assessed with simple sequence repeats. Crop Sci. 40(1):226-232.

Tamura, K., Dudley, J., Nei, M., and Kumar, S. 2007. MEGA4: molecular evolutionary genetics analysis (MEGA) software version 4.0. Molecular biology and evolution. 24(8): 1596-1599.

Tesfaye., K. 2017. Genetic diversity study of sorghum (Sorghum bicolor (L.) Moench) genotypes, Ethiopia. Agriculture and environment. 9 (1): 44-54.

Zheng, LY., Guo, XS., He, B., Sun, LJ., Peng, Y., Dong, SS., Liu, TF., Jiang, S., Ramachandran, S., Liu, CM., and Jing, HC. 2011. Genome-wide patterns of genetic variation in sweet and grain sorghum (Sorghum bicolor). Genome Biolo. 12(11):R114.

\section{How to cite this article:}

Kshirsagar Ram, C., S. Kale Sonam, R. Chavan Narendra and Kore Ganesh, V. 2020. Analysis of Genetic Diversity in Sorghum [Sorghum bicolor (L.)] Accessions of Maharashtra as Estimated by Simple Sequence Repeats (SSR). Int.J.Curr.Microbiol.App.Sci. 9(04): 934-944. doi: https://doi.org/10.20546/ijcmas.2020.904.112 